\title{
Erratum to: Uranium(VI) Adsorption Using a Mixture of 1-Amino-2-naphthol-4-sulfonic Acid and Bentonite: Kinetic and Equilibrium Studies
}

\author{
L. A. Yousef $a$, A. R. Bakry ${ }^{a} *$, and A. A. $\operatorname{Ahmad}^{a}$ \\ a Nuclear Materials Authority, El Maadi, Cairo, 11742 Egypt \\ *e-mail: zarginah@gmail.com
}

Received November 2, 2020; revised November 2, 2020; accepted November 2, 2020

DOI: $10.1134 / \mathrm{S} 1066362220060090$

In the captions of Figs. 7 and $8 \mathrm{pH} 5.5$ should be replaced by 8.5 .

Figure 5 should be replaced by the following:

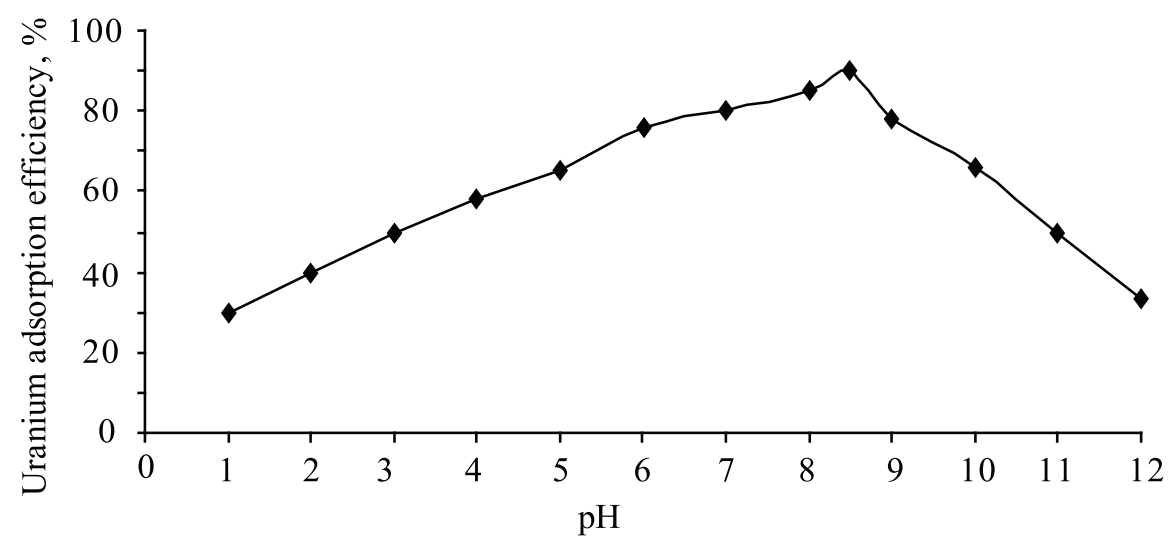

The original article can be found online at https://doi.org/ 10.1134/S1066362220040086 